\title{
Pengaruh Sikap Individu terhadap Budaya Korea pada Keputusan Pembelian: Minat Beli terhadap Produk Merek Kosmetik Korea sebagai Pemediasi
}

\author{
Hendra Setiawan, S.E., M.M. \\ Universitas PGRI Madiun \\ hendrasetiawan@unipma.ac.id
}

\begin{abstract}
Abstrak
Keberadaan Halyu masuk ke negara bagian Asia tenggara termasuk Indonesia sangat besar memberikan dampak perilaku masyarakat yang ada di Indonesia terutama di bidang Fashion. Fenomena tren Halyu mempengaruhi masyarakat Indonesia untuk menggunakan produk Korea. Salah satu produk Korea yang banyak diminati masyarakat Indonesia adalah kosmetik. Sedangkan beberapa brand yang populer di Indonesia seperti nature republics, laneige dan innisfrees. Penelitian ini bertujuan untuk mengetahui pengaruh tren Halyu terhadap keputusan pembelian pada merek kosmetik Korea, akibat meningkatnya penjualan produk kosmetik Korea akhir-akhir ini. Untuk menangani topik ini, Theory of Planned Behavior (TPB) yang dimodifikasi menjadi model penelitian ini. Penelitian ini menggunakan kuesioner sebagai data primernya. Ada 150 Kuisioner yang didistribusikan secara online melalui googleform. Seluruh responden adalah wanita yang berdomisili di Yogyakarta. Analisis data dilakukan dengan menggunakan PLS (partial least square) 6.0. Kemudian dilakukan uji validitas dan reliabilitas dengan menggunakan analisis faktor pada SPSS 16. Hasil penelitian menunjukkan bahwa sikap individu terhadap budaya Korea berpengaruh positif terhadap minat beli pada merek kosmetik Korea, Minat beli merek kosmetik Korea berpengaruh positif terhadap konsumen. keputusan pembelian pada merek kosmetik Korea. Minat beli pada merek kosmetik Korea memediasi pengaruh positif sikap individu terhadap budaya Korea terhadap keputusan pembelian konsumen pada merek kosmetik Korea. Dapat disimpulkan bahwa semua hipotesis dalam penelitian ini dapat diterima dan berpengaruh positif.
\end{abstract}

Keywords : Sikap Individu, Minat beli, Keputusan Pembelian, budaya Korea.

\section{PENDAHULUAN}

Korea Selatan merupakan negara yang berada di Asia Timur yang sangat kental tentang industri kesenian, seperti pertama kali kita mendengar negara Korea Selatan kita dapat menggambarkan mereka memiliki kemajuan di bidang entertainment. Bahkan negara maju seperti Korea, pemasukan terbesar negara tersebut dari industri entertainment. Gelombang Korea sudah mewabah dimana-mana, termasuk diindonesia. Korea Selatan telah menyebarkan "gelombang", yang disebut "gelombang Korea", sejak pertengahan 1990-an (Shim, 2006). Dia mengatakan bahwa pada awalnya, gelombang Korea memperluas budaya kontemporer Korea dan produk budaya hanya di Asia Timur, 
tetapi sejak akhir 1990-an, "gelombang" telah menyebar ke Asia Tenggara, seperti Vietnam, Thailand, Malaysia, Singapura, dan Indonesia.

Karena fenomena tersebut, kesuksesan gelombang Korea pasti memberi dampak besar terhadap status ekonomi Korea Selatan. Gelombang Korea telah berkontribusi 0,2\% dari PDB dengan jumlah \$ 1,308 triliun USD pada tahun 2014 (Roll, 2006). Selain itu, banyak merek Korea dalam berbagai jenis produk seperti kosmetik, mobil, dan sebagainya terus berkembang. Jumlah wisatawan yang melakukan perjalanan ke Korea Selatan, khususnya di lokasi pemotretan diperkirakan sekitar 700.000 orang pada tahun 2014 . Pendapatan film-film Korea dari box office luar negeri telah menghasilkan $\$ 80$ juta pada tahun 2015 (Ramesh, 2005). Bersamaan dengan bukti-bukti itu, seperti yang telah terjadi di Vietnam dan Thailand, bahwa gelombang Korea memiliki pengaruh terhadap status ekonomi Korea Selatan dengan menerapkan beberapa bintang Korea untuk menjadi duta atau juru bicara untuk mempromosikan produk atau merek mereka, seperti komputer, ponsel, mobil, kosmetik dan gadget elektronik lainnya. Peneliti ingin mengetahui dampaknya dengan cara mencari pengaruh: sikap individu, minat beli dan keputusan pembelian terhadap merek kosmetik Korea. Berdasarkan beberapa penelitian sebelumnya milik Kusbianto, (2013), Montjai, Tewal, Lengkong, (2014) dan putri, (2011), bahwa produk-produk Korea sangat diminati menunjukan bahwa sikap, dan minat beli sangat mempengaruhi konsumen pada keputusan akhir. Penulis ingin mencoba untuk melengkapi kesenjangan yang ada dan memberik pandangan baru tentang pengaruh sikap individu pada keputusan pembelian, penulis berharap dengan adanya sikap individu maka akan meberi gambarang yang lebih keputusan pembelian. Oleh karena itu, Peneliti ingin mengetahui dampak dari gelombang Korea terhadap keputusan orang Indonesia untuk membeli produk Korea dengan menerapkan Theory of Planned Behaviour (TPB). Sedangkan di negara-negara lain seperti Cina, Vietnam, Thailand, dan Jepang penjualan produk Korea telah meningkat secara signifikan, penelitian ini akan mengamati apakah orang Indonesia juga mau dan akhirnya memutuskan untuk membeli produk kosmetik Korea sejak studi sebelumnya yang menganalisis tentang budaya Korea masih sangat terbatas.

\section{LANDASAN TEORI}

Theory of planned behaviour (TPB) merupakan perpanjangan dari theory of reasoned action (TRA) yang diusulkan oleh (Ajzen., 1991). Sebagaimana dibahas oleh Liska (1984), dan peneliti lain Sheppard (1988), theory of reasoned action tidak dapat menangani perilaku yang membutuhkan sumber daya, kerja sama, dan keterampilan. Menanggapi kritik tentang model Ajzen (1985), mengusulkan model yang disesuaikan disebut theory of planned behavior. Teori ini berpendapat bahwa niat individu untuk melakukan perilaku dipengaruhi oleh kombinasi sikap perilaku (yaitu keyakinan seseorang tentang keinginan perilaku); norma subyektif (yaitu relevansi dan kepentingan orang yang dianggap penting oleh orang lain yang signifikan); dan kontrol perilaku (yaitu perasaan mengontrol perilaku seseorang) (Ajzen., 1991). Theory of reasoned action secara luas digunakan dalam studi empiris untuk peramalan perilaku manusia (Ajzen., 1991), (Mathieson, 1991), (Sparks \& Shepherd, 1992) dan telah menerima dukungan luas dalam studi empiris konsumsi dan sosial literatur terkait psikologi (Ajzen., 1991). Dalam hal perilaku yang sulit dilakukan, TPB telah terbukti lebih dapat diterapkan daripada TRA. Dibandingkan dengan TRA, TPB menambahkan perceived behavioral control sebagai penentu niat prilaku. Dalam makalah ini, diharapkan bahwa TPB, yang oleh penelitian sebelumnya berhasil telah diterapkan untuk tujuan memahami sikap konsumen 
kosmetik Korea. mungkin cocok untuk menganalisis hubungan antara gelombang Korea dan keputusan orang Indonesia untuk membeli produk Korea (Kusbianto, 2013).

\section{METODE PENELITIAN}

Penelitian ini menggunakan penelitian kualitatif dengan menggunakan data primer. Penelitian ini mengambil data dengan mengumpulkan dari Kuesioner yang disebarkan melalui media sosial pada 23-30 september 2019. Kuesioner berisi indikator-indikator dalam variabel. Seratus lima puluh responden disebar secara acak selama seminggu. Mereka diminta untuk mengisi kuesioner berbasis online. Semua responden adalah wanita yang tinggal di Yogyakarta.

Tekhnik analisis data dalam penelitian ini meliputi : uji validitas, uji reliabilitas, statistik deskriptif, uji pengaruh langsung, dan uji pengaruh tidak langsung.

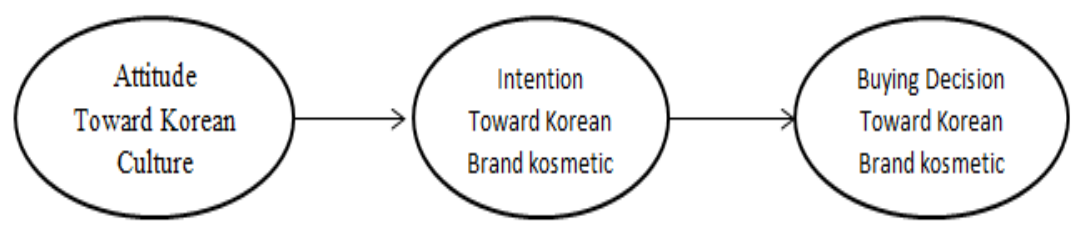

Gambar 1. Diagram Alur Penelitian

\section{HASIL DAN PEMBAHASAN}

Validitas pengukuran dinilai berdasarkan kriteria nilai faktor loading item minimal 0,4 menurut (Hair, Anderson, Babin, \& Black, 2010). Hal ini dapat dilihat bahwa pada variabel sikap individu semua item valid, sikap lingkungan juga valid, minat beli juga valid, dan keputusan pembelian semuanya juga valid. Karena factor loading lebih dari 0,4 , sehingga semua item masuk dalam hipotesis.

Tabel 1. Hasil Uji Validitas

\begin{tabular}{|l|l|c|c|}
\hline \multicolumn{1}{|c|}{ Variabel } & \multicolumn{1}{c|}{ Butir } & Butir Valid & Butir tidak Valid \\
\hline Sikap Individu & Sik1-sik5 & Semua Valid & - \\
\hline Minat Beli & Mbk1-mbk4 & Semua Valid & - \\
\hline Keputusan Pembelian & Kpk1-kpk6 & Semua Valid & - \\
\hline
\end{tabular}

Reliabilitas pengukuran diperiksa berdasarkan nilai alpha Cronbach (>0,8). Pada Tabel 2, dapat dilihat bahwa nilai Alpha Cronbach untuk setiap variabel melebihi nilai ambang 0,8 . Semakin besar nilai alpha Cronbach semakin baik instrumen penelitian. Ini menunjukkan variabel-variabel yang lain dapat digunakan untuk analisis lebih lanjut.

Tabel 2. Hasil Uji Reliabilitas

\begin{tabular}{|l|c|c|}
\hline \multicolumn{1}{|c|}{ Variabel } & Cronbach's Alpha & Kategori \\
\hline Sikap Individu & 0,931 & Sangat Reliabel \\
\hline Minat Beli & 0,958 & Sangat Reliabel \\
\hline Keputusan Pembelian & 0,949 & Sangat Reliabel \\
\hline
\end{tabular}


Statittik deskriptif mean, standar deviasi dan korelasi antara variabel penelitian disajikan pada tabel 3. Seperti yang ditunjukkan, minat beli berkorelasi dengan status pekerjaan ( $\mathrm{r}$ $=-0,30, \mathrm{p}<0,01)$, sikap individu $(\mathrm{r}=0,678, \mathrm{p}<0,01)$, dan Keputusan pembelian berkorelasi dengan status pekerjaan $(\mathrm{r}=-0,182, \mathrm{p}<0,01)$, sikap individu $(\mathrm{r}=0,566, \mathrm{p}$ $<0,01)$, dan minat beli $(\mathrm{r}=0,834, \mathrm{p}<0,01)$.

\begin{tabular}{lcccccccc}
\hline \multicolumn{1}{c}{ Variabel } & Mean & SD & 1 & 2 & 3 & 4 & 5 & 6 \\
\hline 1. Usia & - & - & - & - & - & - & - & - \\
2. PT & - & - & $0,355^{* *}$ & - & - & - & - & - \\
3. SP & - & - & $0,211^{* *}$ & $0,287^{* *}$ & - & - & - & - \\
4. PR & - & - & $0,193^{* *}$ & $0,238^{* *}$ & $0,225^{* *}$ & - & - & - \\
5. SIK & 4,11 & 1,56 & $-0,134$ & $-0,135$ & $-0,21^{* *}$ & $-0,79$ & - & - \\
6. MBK & 4,24 & 1,90 & $-0,138$ & $-0,064$ & $-0,30^{* *}$ & 0,031 & $0,678^{* *}$ & - \\
7. KPK & 2,33 & 1,66 & $-0,092$ & $-0,005$ & $-0,182^{*}$ & 0,115 & $0,566^{* *}$ & $0,834^{* *}$
\end{tabular}

Tabel 4 menunjukkan hasil pengujian hipotesis. Hipotesis pertama diterima. sikap individu terhadap budaya Korea berpengaruh signifikan dan positif pada minat beli terhadap merek kosmetik Korea. Hal ini sesuai dengan pendapat (Kusbianto, 2013) bahwa sikap individu terhadap minat beli memungkinkan seorang konsumen untuk mendapatkan kesenangan dengan membeli produk kosmetik Korea, yang berarti secara positif ini mempengaruhi minat beli konsumen.

Hipotesis kedua diterima. Hal ini dipicu dengan pendapat (Maghfiroh, Arifin, \& \&, 2013) mengemukakan bahwa yang dapat memengaruhi minat dalam membeli terhubung dengan perasaan dan emosi, bila konsumen merasa cocok dan memuaskan dalam membeli dan melakukan transaksi produk maka hal itu akan memperkuat minat membeli, ketidakpuasan biasanya menghilangkan minat. Jadi, minat beli mempengaruhi keputusan pembelain secara positif terhadap produk kosmetik Korea.

Hipotesis ketiga diterima. Terbukti bahwa seseorang yang selalu mencari informasi mengenai produk yang diminatinya dan mencari informasi untuk mendukung sifat-sifat positif dari produk tersebut (Ferdinand, 2002). Terbukti bahwa semakin besar minat beli terhadap merek kosmetik Korea yang dipengaruhi sikap individu terhadap budaya Korea, maka semakin tinggi pula keputusan pembelian terhadap merek kosmetik Korea.

\begin{tabular}{|c|l|c|c|c|}
\hline No. & \multicolumn{1}{|c|}{ Hipotesis } & Estimate & P & Keterangan \\
\hline H1 & $\begin{array}{l}\text { Terdapat pengaruh positif sikap } \\
\text { individu terhadap budaya Korea pada } \\
\text { minat beli terhadap merek kosmetik } \\
\text { Korea }\end{array}$ & 0,64 & $<0,01$ & Didukung \\
\hline H2 & $\begin{array}{l}\text { Terdapat pengaruh positif minat beli } \\
\text { terhadap merek kosmetik Korea pada } \\
\text { keputusan pembelian merek kosmetik } \\
\text { Korea }\end{array}$ & 0,87 & $<0,01$ & Didukung \\
\hline
\end{tabular}

\begin{tabular}{|c|c|c|c|c|}
\hline No. & \multicolumn{1}{|c|}{ Hipotesis } & Estimate & P & Keterangan \\
\hline H3 & $\begin{array}{l}\text { Minat beli terhadap merek kosmetik } \\
\text { Korea memediasi pengaruh positif }\end{array}$ & 0,543 & $<0,001$ & Didukung \\
\hline
\end{tabular}




\begin{tabular}{|l|l|l|l|l|}
\hline $\begin{array}{l}\text { sikap individu terhadap budaya Korea } \\
\text { pada keputusan pembelian terhadap } \\
\text { merek kosmetik Korea }\end{array}$ & & \\
\hline
\end{tabular}

\section{KESIMPULAN}

Berdasarkan analisis hasil hubungan sikap individu terhadap budaya Korea pada keputusan pembelian terhadap kosmetik merek Korea dengan minat beli terhadap merek kosmetik Korea sebagai variable mediasi, semua hipotesis dalam penelitian ini didukung. Terbukti bahwa budaya Korea, konsumen dengan sikap individu terhadap budaya Korea yang tinggi cenderung lebih memiliki keinginan dalam pembelian kosmetik Korea dibandingkan konsumen dengan sikap individu terhadap budaya Korea yang rendah. Maka tampak bahwa kunci sukses utama perusahaan- perusahaan kosmetik untuk menarik minat konsumen dalam pembelian kosmetik Korea yaitu pengaruh langsung budaya Korea terhadap konsumen baik individu tersebut dan lingkungannya. Seperti aktor, artist, film, dan penyanyi yang mempromosikan kosmetik tersebut.

\section{DAFTAR PUSTAKA}

Abdillah, W., \& Hartono, J. (2015). Partial Least Square (PLS): Alternatif Structural Equation Modeling (SEM) Dalam Penelitian Bisnis. Yogyakarta: Penerbit Andi, $22,103-150$.

Ajzen, I. \&. (1975). Belief, attitude, intention dan behavior: An introduction to theory dan research. Prentice-Hall, 11, 56-85.

Ajzen, I. (1985). From Intentions to Actions: A Theory of Planned Behavior. 11-39.

Ajzen, I. (1991). The Theory of Planned Behavior. Organizational Behavior and Human Decision Processes, 50, 179 - 211.

Ajzen, I., \& Driver, B. L. (1992). Application of The Theory of Planned Behavior to Leisure Choice. Journal of Leisure Research, 24(3), 207-224.

Ajzen, I., \& Fishbein, M. (1972). Attitudes and normative beliefs as factor influencing behavioral intentions. personality and psychology, 21, 23-34.

Ajzen, I., \& Madden, T. J. (1986). Prediction of Goal-Directed Behavior:

Attitudes,Intentions, And Perceived Behavioral Control. Journal of Experimental Social Phsycology, 22, 453-474.

Aldo. (2017). Hubungan antara Big Five Personalities, Motivation to Fake, dan Applicant Faking Behavior. Tesis, 14-18.

Amstrong, \& Kotler. (2008). Prinsip-prinsip Pemasaram. Erlangga, 12, 209-219.

Assael. (1998). Pembelian Ulang. Universitas Gajah Mada, 19, 40-42.

Bagozzi, R. P., \& Warshaw, P. R. (1990, September). Trying to consume. Journal of Consumer Research, 17, 127-140.

Belch, G. a. (2004). Advertising And Promotion: An Integrated Marketing Commnunications Perspective. The McGraw Hill/Irwin: New York, 6, 7-9.

Broderick and Pickton, A. (2005). Sikap. Dipetik 2018, dari library.binus.ac.id: library.binus.ac.id/eColls/eThesisdoc/Bab2/2013-2-01546-MC\%20Bab2001.pdf

Busler. (2000). Manajemen Strategik dan Pemasaran. Department of Management, Faculty of Economics and Business, , 20-23. 
Cho, H. J. (2005). Reading the 'Korean Wave' as a Sign of Global Shift. Korea Journal, $3,147-182$.

Chung, S. S., Young, D. C., \& Seung, H. K. (2005). The Korean Wave in Southeast Asia: An Analysis of Cultural Proximity and the globalisation of the Korean Cultural Products. International Journal of Literature and Arts, 24, 136-141.

Engel, e. a. (1995). Consumer Behavior. The Dryden Press, Hartcourt Brace College Publisher, 141-154.

Ferdinand, A. (2002). Pengembangan Minat Beli merek ekstensi (Vol. 4). Semarang: Universitas Diponegoro.

Franssiska, D. E. (2014). Transformasi Nilai Korean Wave Terhadap Sikap Nasionalisme Remaja (Vol. 3). Bandung: repository.upi.edu

Ghozali, I. (2014). Structural Equation Modeling, Metode Alternatif dengan Partial Least Square (PLS). Badan Penerbit Universitas Diponegoro, 4, 201-230.

Hair, e. a. (2010). Uji Validitas. Upper Saddle River-Prentice Hall. New Jersey., 317.

Hair, e. a., Anderson, J. F., Tatham, R. L., \& Black, W. C. (2006). Multivariate Data Analysis. Prentice-Hall International, Inc, 6, 11-13.

Huang, X. (2009, August 8). =Korean Wave' - The Popular Culture, Comes as Both Cultural and Economic Imperialism in the East Asia. Asian social Science, 5(8), 181-192.

Kaparang, O. M. (2013). Analisa Gaya Hidup Remaja SMAN 9 Manado Dalam Mengimitasi Budaya Pop Korea Melalui Televisi. Universitas Jenderal Soedirman, 3-5.

Kotler, P. A. (2012). "Pengaruh Iklan Televisi dan Harga Terhadap keputusan Pembelian Sabun Lux”. Jurnal Riset Sains Indonesia.

Kotler, P., \& Amstrong, G. (2007). Prinsip-prinsip Pemasaran. Erlangga, 12(1 dan 2), 102-122.

Kotler, P., \& Keller, K. L. (2008). Manajemen Pemasaran (Vol. Edisi 1). Jakata: Erlangga.

Kotler, P., Bowen, J., \& Makens, J. (1999). Marketing for hospitality and tourism. International ed, New Jersey: Prentice Hall, 22, 5-9.

Kusbianto, A. O. (2013). The Impacts of Korean Wave Towards Indonesia People's Decisions in Buying Korean Products: Implementation of the Modofication of Theory of Planned Behavior. repository.uksw.edu, 3, 3-20.

Lee, H. E. (2005). Othering ourselves: Identity and globalization in Korean popular music, 1992 - 2002' Ph.D. Dissertation, The University of Iowa., 8, 46-67.

Liska, A. E. (1984). A Critical Examination of Causal Structure of the Fishbein/Ajzen Attitude Behaviour Model. social psychology Quarterly, 47(1), V61-74.

Lita, R., \& Cho, Y. C. (2012). The Influence Of Media On Attitudinal And Behavioral Changes: Acceptance Of Culture And Products. International Business \& Economics Research Journal, 11(12), 213-221.

Maghfiroh, A., Arifin, Z., \& \&. S. (2013). Pengaruh Citra Merek terhadap Minat Beli dan Keputusan Pembelian. Fakultas Ilmu Administrasi . Universitas Brawijaya, Malang, 3, 18-23.

Mariani, E. (2012). Delicious Boys Leas Hallyu in Indonesia. Korean Wave, ed. The Korea Herald, Paju: Jimoondang. 
Mathieson, K. (1991). Predicting User Intentions: Comparing the Technology Acceptance Model with the Theory of Planned Behavior. Itrformatiort Systems Research, 2, 173-191.

Miller, L. (2008). Korean TV dramas and the Japan-style Korean wave.Bnet. Dipetik August wednesday, 2018, dari findarticles.com: http://findarticles.com/p/articles/mi_go1931/is_3_27/ai_n31591146/

Montjai, O., Tewal, B., \& \& lengkong, V. P. (2014). MotivasiI, Sikap dan Minat Beli Konsumen Pengaruhnya terhadap Keputusan Pembelian Sepeda Motor Yamaha PT. Hasjrat Abadi. EMBA, Vol.2 Hal. 35-45.

Potipan, P., \& \& Worrawutteerakul, N. (2010). A Study of the Korean Wave in order to be a Lesson to Thailand fos Establishing a Thai Wave. Malardalen University, 25.

Purba, J. (2002). Pengelolaan Lingkungan Sosial. Yayasan Obor Indonesia, 2, 1-7. Putri, W. O. (2011). Pengaruh Budaya Korean Pop dalam Tayangan Top Kpop Tv Terhadap Perilaku Remaja di BSD, Kencana Loka Blok F1. Universitas Bina Nusantara, 5, 4-8.

Ramesh, B. (2005). A Hallyu Story. Dipetik July 7, 2018, dari www.wpp.com: http://www.wpp.com/nr/rdonlyres/7e5c1958-653e-481c-aed1e356ef0e8dd2/0/insidewpp_atticus2005_bharadwajrameshgroupm_atticus2005_ jul06.pd

Rizky, N. (2015, july 15). Budaya Pop Korea Merasuki Indonesia. Dipetik may 13, 2018, dari nasutionrizky.com: http://nasutionrizky.com/budaya-pop-korea-merasukiindonesia/

Roll, M. (2006). Letter from Asia: The Korean Wave - driving Korean brands. Dipetik August 2, 2018, dari noise: http://brandnoise.typepad.com/brand_noise/2006/09/the_korean_wave.html

Schiffman, L. a. (2000). Consumer Behavior,. International Ed. Prentice Hall International, 25, 56-62.

Sheppard, B. H. (1988). "The Theory of Reasoned Action: A Meta-Analysis of Past Research with Recommendations for Modifications and Future Research. Journal of Consumer Research, 15(3), 325-343.

Shim, D. (2006). Hybridity and the Rise of Korean Popular Culture in Asia. Media Culture and Society, 28(1), 25-44.

Sparks, P. a. (1992). Self- identity and the theory of planned behavior: assessing the role of identification with 'green consumerism. Social Psychology, 55(4), 388-99.

Spears, N. a. (2004). Measuring Attitude Toward the Brand and Purchase Intentions. Current Issues and Research in Advertising, 27, 24-30.

Stroz. (1987). Lingkungan Sosial. Universitas Gajah Mada, 31, 54-76.

Sue, J. L. (2011). The Korean Wave: The Seoul of Asia. The Elon Journal of Undergraduate Research in Communications, 2(1), 98-102.

Swastha, B. (2007). Manajemen Pemasaran Modern. Liberty Offset, Yogyakarta, 23, 3334.

Setiawan, H. (2018). Hubungan antara Sikap Individu dan Sikap Lingkungan terhadap budayaKorea pada Keputusan Pembelian: Minat Beli terhadap Produk Kosmetik Korea sebagai Pemediasi. Yogyakarta. Pustakawan STIE YKPN. repository.stieykpn.ac.id/id/eprint/183.

Taylor, S., \& Todd, P. A. (1995). Understanding Information Technology Usage:A Test of Competing Models. Information Systems Research, 20(6), 144-176. 
Truong Thi Hoang Long, a. H. (2012). The Effecst of Halyu on Purchasing Behaviorand Intention to Buying Korean Product. Vietnam National University Hochiminh City International University School of Business, 32, 15.

Tung, L. C. (2011). The Impact of Entrepreneurship Education on. Run Run Show Library, 24, 56.

Yasumoto, S. (2006). The impact of the Korean wave on japan: A case study of the influence of trans-border electronic communication and the trans-national programming industry. Department of japanese Studies, School of Languages and Cultures. The University of Sydney, 25, 21. 